\title{
Lower TSH and higher free thyroxine predict incidence of prostate but not breast, colorectal or lung cancer
}

\author{
Yi X Chan 1,2, Matthew W Knuiman ${ }^{3}$, Mark L Divitini', Suzanne J Brown ${ }^{4}$, \\ John Walsh ${ }^{1,4}$ and Bu B Yeap ${ }^{1,2}$ \\ ${ }^{1}$ School of Medicine, The University of Western Australia, Crawley, Western Australia, Australia, \\ ${ }^{2}$ Department of Endocrinology and Diabetes, Fiona Stanley Hospital, Western Australia, Australia, \\ ${ }^{3}$ School of Population Health, The University of Western Australia, Crawley, Western Australia, Australia, \\ ${ }^{4}$ Department of Endocrinology and Diabetes, Sir Charles Gairdner Hospital, Nedlands, Western Australia, Australia
}

Correspondence should be addressed to B B Yeap

Email

bu.yeap@uwa.edu.au

\begin{abstract}
Context: Thyroid hormones modulate proliferative, metabolic and angiogenic pathways. However few studies have examined associations of thyroid hormones with cancer risk.

Objectives: To explore associations of thyrotropin (TSH), free thyroxine (FT4) and anti-thyroperoxidase antibodies (TPOAb) with the incidence of all (non-skin) cancers and specific common cancers.

Design and setting: A prospective cohort study of a community-dwelling population aged 25-84 years in Western Australia.

Main outcome measures: Archived sera from 3649 participants in the 1994/1995 Busselton Health Survey were assayed for TSH, FT4 and TPOAb. Cancer outcomes until 30 June 2014 were ascertained using data linkage. Longitudinal analyses were performed using Cox proportional hazards regression.

Results: During 20-year follow-up, 600 participants were diagnosed with non-skin cancer, including 126, 100, 103 and 41 prostate, breast, colorectal and lung cancers respectively. Higher TSH was associated with a lower risk of prostate cancer after adjusting for potential confounders, with a 30\% lower risk for every $1 \mathrm{mIU} / \mathrm{L}$ increase in TSH (adjusted hazard ratio (HR): $0.70,95 \%$ confidence interval $(\mathrm{Cl}): 0.55-0.90, P=0.005)$. Similarly, higher FT4 was associated with an increased risk of prostate cancer (adjusted HR: 1.11 per 1 pmol/L increase, $95 \% \mathrm{Cl}: 1.03-1.19, P=0.009$ ). There were no associations of TSH, FT4 or TPOAb with all non-skin cancer events combined, or with breast, colorectal or lung cancer. Conclusion: In a community-dwelling population, lower TSH and higher FT4 were associated with an increased risk of prostate cancer. Further studies are required to assess if thyroid function is a biomarker or risk factor for prostate cancer.
\end{abstract}

\section{Introduction}

Thyroid hormones modulate cellular growth, metabolism and differentiation through binding of the active thyroid hormone tri-iodothyronine (T3) to thyroid hormone receptors leading to activation of genomic (nuclear) pathways (1). Non-genomic actions of T3 have also been described, with liganded thyroid hormone receptors shown to activate the phosphatidylinositol 3-kinase
() 2017 European Society of Endocrinology Printed in Great Britain
(PI3K)-Akt/protein kinase B (PKB)-mammalian target of rapamycin (MTOR)-p70 ${ }^{\mathrm{S} 6 \mathrm{~K}}$ pathway independent of DNA binding $(2,3)$. This pathway is involved in cellular proliferation, growth and survival, and dysregulation of PI3K signaling is present in a large proportion of human cancers (4). T3 can also bind directly to the integrin $\alpha \mathrm{V} \beta 3$ transmembrane receptor, regulating hypoxia-inducible

Published by Bioscientifica Ltd. 
factor (HIF) 1A expression through PI3K signaling (5). Binding of both thyroxine (T4) and $\mathrm{T} 3$ to this receptor can also activate the extracellular signal kinases 1 and 2 (ERK1/2) cascade $(6,7)$, which leads to modulation of angiogenesis $(5,7)$. Furthermore, increased type 3 deiodinase (DIO3) expression has been observed in several highly proliferative cancers (8). Since DIO3 is an inactivating enzyme for thyroid hormones, this suggests a role for modulation of thyroid hormones at a cellular level in influencing tumor proliferation. Given the potential of thyroid hormones to affect cellular metabolic, proliferative and angiogenic pathways, it is plausible that thyroid hormones may influence tumor growth and survival. In addition to this, thyroid hormones also increase liver production of sex hormone binding globulin (SHBG), and hyperthyroidism is associated with higher SHBG levels $(9,10)$. Changes in thyroid function may therefore affect circulating sex hormone concentrations, which may have an effect on sex-hormone-sensitive organs such as the prostate gland.

These findings have been supported by mechanistic studies demonstrating inhibition of lung and prostate tumor cell growth in rodent xenograft models where hypothyroidism was induced using propylthiouracil (11, 12). Conversely, studies of colorectal cancer stem cells that have increased expression of DIO3 had decreased engrafting capacity in immunodeficient mice when these cells were treated with $\mathrm{T} 3$, and decreased in vitro clonogenic potential and in vivo tumor growth when knockdown studies of DIO3 were performed to increase intracellular T3 (13). Epidemiological studies examining the association of thyroid hormones with cancer incidence have been limited by cross-sectional or retrospective design $(14,15,16,17)$, or lack of biochemical measurements of thyroid hormone concentrations to classify thyroid hormone status $(15,17$, $18,19)$. Few prospective studies have been performed, and most did not utilize time-to-event analyses for reporting of outcomes $(18,20,21,22)$. Two large prospective studies have reported an association of hyperthyroidism with the incidence of any cancer $(23,24)$ : lung $(23,24)$, breast (23), and prostate cancer (24). However, these findings were not observed in a prospective study of older men where an association of higher thyrotropin (TSH) with lower incidence of colorectal cancer was observed (25). An association of autoimmune thyroid disease and breast cancer has previously been implicated (26), however two studies with pre-diagnostic levels of anti-thyroperoxidase antibodies (TPOAb) have shown conflicting results (21, 22). Therefore, further studies of well-characterized cohorts will help to clarify associations of thyroid hormones and thyroid autoimmunity with cancer outcomes.

Variation of thyroid hormone levels within population reference ranges has been associated with a range of adverse health outcomes (27). Given the burden of health attributed to cancer, and the relative ease with which thyroid hormones can be manipulated, identification of novel hormone biomarkers of cancer incidence is an important initial step in the identification of potential therapeutics. Therefore, the aim of this study was to investigate whether circulating levels of TSH, free thyroxine (FT4) or TPOAb were associated with risk of cancer outcomes in a general community adult cohort independent of other risk factors for cancer, and sex hormone concentrations.

\section{Methods}

\section{Study population and participants}

The population of Busselton, a coastal area in the southwest of Western Australia, has been regularly surveyed since the Busselton Health Study was established in 1966 (28). More than $90 \%$ of this population consists of individuals with Anglo-Celtic ancestry. In 1994/1995, a follow-up health survey of survivors from previous surveys was conducted as previously described (29). A total of 4843 participated in the survey and provided a blood sample. Western Australia is considered an iodinesufficient area (30).

Participants were excluded if they were aged outside the range of 25-84 years (377), if they had a history of cancer (198) or were taking thyroid-related medications at baseline (147). Those with missing TSH, FT4 or TPOAb data (208), those with overt hyper- or hypo-thyroidism (75), and those with missing data on key confounders (121) were also excluded. To avoid the potential of reverse causation, participants who died or were diagnosed with cancer within the first 2 years of follow-up were further excluded (68) leaving a total of 3649 (1623 men and 2026 women) for analyses.

\section{Baseline measurements and cancer outcomes}

Participants in the 1994/1995 survey completed a comprehensive health and lifestyle questionnaire, underwent various measurements and tests, and provided a blood sample (29). Information on marital status, occupation, menopausal status/oral contraceptive use/ hormone replacement therapy use (women only), smoking, 
alcohol intake, minutes of moderate and vigorous leisure time physical activity per usual week, diabetes and use of medications was obtained by questionnaire. Leisure time physical activity was calculated as (min/week of moderate activities $)+2 \times(\mathrm{min} /$ week of vigorous activity) and categorized as $(0-149,150+\mathrm{min} /$ week $)$ where $150 \mathrm{~min} /$ week is the recommended level of physical activity sufficient for health benefits (31). Alcohol consumption was categorized as light, moderate and heavy if intake was $<140 \mathrm{~g} /$ week, $140-420 \mathrm{~g} /$ week and $>420 \mathrm{~g} /$ week respectively. Anthropometric measures were obtained using standardized protocols by trained assessors, which included measurements of weight and height. Body mass index was defined as weight (kg) divided by height (m) squared. Thyroid-related medications were defined as medications potentially affecting thyroid function or thyroid function tests. These included thyroxine supplementation or anti-thyroid medications, lithium, amiodarone, carbamazepine or phenytoin use. Overt hyperthyroidism was defined as TSH $<0.4 \mathrm{mIU} / \mathrm{L}$ and FT4 $>21.2 \mathrm{pmol} / \mathrm{L}$, and overt hypothyroidism was defined as TSH $>4.0 \mathrm{mIU} / \mathrm{L}$ and FT $4<12.6 \mathrm{pmol} / \mathrm{L}$.

Blood samples were obtained from the participants after an overnight fast at the time of survey, and the serum was separated and stored at $-70^{\circ} \mathrm{C}$. Serum biochemical measurements of TSH, FT4 and TPOAb were done in three batches in 2007, 2011 and 2013 and assayed using an Immulite 2000 chemiluminescent analyzer (Siemens Healthcare Diagnostics Products, Deerfield, IL, USA) as previously described (32). The TSH assay is a thirdgeneration assay, calibrated against the international reference preparation MRC 80/558. The TPOAb assay was calibrated against MRC 66/387. Methods for measurement of TSH and TPOAb were consistent throughout all runs. The FT4 method was a single-step, labeled hormone analog method that was re-standardized by the manufacturer between 2007 and 2011. Based on data from 717 samples assayed in six laboratories (as supplied by the manufacturer), the 2007 values were converted to align with the 2011/2013 method, as previously described (33). In each run, between 2 and 4 quality control samples were included. Reference ranges were as follows: TSH, 0.4$4.0 \mathrm{mIU} / \mathrm{L} ; \mathrm{FT} 4,12.6-21.2 \mathrm{pmol} / \mathrm{L}$ (to convert to $\mathrm{ng} / \mathrm{dL}$, multiply by 0.078 ); and TPOAb less than $35 \mathrm{kIU} / \mathrm{L}$. Serum testosterone (T) was measured using liquid chromatography tandem-mass spectrometry without derivatization using atmospheric pressure photoionization for positive mode (34). Between-run imprecision was $8.6 \%$ and $7.9 \%$ at $\mathrm{T}$ concentrations of $5.3 \mathrm{nmol} / \mathrm{L}$ and $26.9 \mathrm{nmol} / \mathrm{L}$ respectively. SHBG was assayed using a solid-phase, two-site enzyme immunometric assay with chemiluminescent substrate (Immulite 2000xPi; Siemens Healthcare) with between-run imprecision of $3.4 \%$ at $39.4 \mathrm{nmol} / \mathrm{L}$. Laboratory scientists were blinded to the outcome events.

The Human Research Ethics Committee of the Department of Health of Western Australia (Project number 2011/60) gave permission to access the cancer and death records of the survey participants for the period 1 January 1980 to 30 June 2014 using record linkage to the cancer registrations and deaths (35). International Classification of Diseases, 9th revision (ICD-9) codes were used up to 30 June 1999, and ICD10 codes were used for subsequent events. History of cancer at baseline in 1994/1995 was based on any cancer registration during the 15 years before the survey (i.e., 1980-1994/1995). Cancer outcome events during the 20-year follow-up from survey attendance in 1994/1995 to 30 June 2014 were from cancer and death records during this period. Five outcome events were analyzed where the event was cancer registration or cancer death. These outcomes included time to first fatal or non-fatal cancer, which included all cancer types apart from skin cancer (ICD-10 C00-C42, C45C97). Outcomes for specific cancer types including prostate cancer (men only, ICD-10 C61), breast cancer (women only, ICD-10 C50), colorectal cancer (ICD-10 C18-C21) and lung cancer (ICD-10 C33-C34) were also analyzed separately.

\section{Statistical analyses}

Statistical analyses were performed using SAS 9.4. The associations between thyroid risk factors (TSH, FT4 and $\mathrm{TPOAb}$ ) and cancer outcomes were examined using Cox proportional hazards regression modeling. Risk factors were examined as a continuous variable and in quartile categories. In addition, TSH was examined using categories $<0.4,0.4-4.0$ and $>4.0 \mathrm{mIU} / \mathrm{L}$ and TPOAb using categories $<35.0$ and $\geq 35.0 \mathrm{kIU} / \mathrm{L}$ according to their respective reference ranges. The estimated hazard ratios (HRs) with 95\% CI and $P$ value are reported for each risk factor in relation to each of the five cancer outcomes after two levels of adjustment for potential confounders. Model A included each hormone variable of interest (i.e. TSH, FT4 or TPOAb) adjusted for age and sex (not in sex-dependent cancers), and Model B was further adjusted for marital status, occupation, smoking, alcohol consumption, leisure time physical activity (LTPA) 150+ min/week, BMI, diabetes and menopausal status/oral contraceptive 
use/hormone replacement therapy use (women only). Additional adjustments for SHBG and T were included in the prostate cancer model. Model-based structure parameters for the secretory capacity of the thyroid gland (SPINA-GT) and pituitary thyrotroph function (TSH Index or TSHI) were also calculated using equations provided by Dietrich et al. (36) and Jostel et al. (37) to further assess contribution of the thyroid and pituitary gland to overall thyroid function. These calculations were applied to the prostate cancer analysis. Interactions between hormone variables and sex were also explored for all (non-skin) cancers: colorectal and lung cancers. A $P$ value of $<0.05$ or a CI that did not cross 1.0 was considered significant.

\section{Results}

\section{Baseline characteristics and outcome events}

Baseline characteristics of the cohort, stratified according to gender, are presented in Table 1 . The mean age was 51 years, mean BMI was $26.2 \mathrm{~kg} / \mathrm{m}^{2}, 16 \%$ of men and $10 \%$ of women were current smokers, $38 \%$ of men and $8 \%$ of women were moderate/heavy drinkers, $45 \%$ met the threshold for sufficient physical activity, $6 \%$ had diabetes, and $52 \%$ of women were post-menopausal and a third of these women used hormone replacement therapy. Oral contraceptives were used by $24 \%$ of pre-menopausal women. Mean \pm S.D. for TSH was $1.48 \pm 1.03 \mathrm{mIU} / \mathrm{L}$ with $2.5 \%$ having level $<0.4 \mathrm{mIU} / \mathrm{L}$ and $2.1 \%$ having level $>4.0 \mathrm{mIU} / \mathrm{L}$. Mean \pm s.D. for FT 4 was $16.0 \pm 2.3 \mathrm{pmol} / \mathrm{L}$. Mean \pm S.D. for TPOAb was $50.0 \pm 291.5 \mathrm{kIU} / \mathrm{L}$ with $11.8 \%$ having TPOAb $\geq 35.0 \mathrm{kIU} / \mathrm{L}$.

During the 20-year follow-up period a total of 600 (16\%) participants had a non-fatal or fatal non-skin cancer event, 126 (8\%) men and 100 (5\%) women were diagnosed with prostate and breast cancer respectively, 103 (3\%) participants developed colorectal cancer and 41 (1\%) had a lung cancer event (Table 1).

\section{Associations of TSH, FT4 and TPOAb with cancer events}

Adjusted HRs for TSH, FT4 and TPOAb in relation to the five cancer outcomes are shown in Tables 2, 3, 4, 5 and 6. TSH and FT4 as continuous variables were examined before and after natural log transformation. TPOAb was only examined after log transformation as it was heavily skewed to the right. There was no evidence of any relationship between TSH, FT4 and TPOAb in continuous or categorical forms with all (non-skin) cancers (Table 2).
There was an inverse association of TSH and a positive association of FT4 (but not TPOAb) with prostate cancer in men (Table 3). No associations of thyroid hormones or TPOAb were observed with breast, colorectal or lung cancers (Tables 4, 5 and 6). Interactions were tested to see if the relationship was different in men and women for all (non-skin) cancers: colorectal and lung cancers, but all were not significant (data not shown). Post hoc power calculations for non-significant results showed over $80 \%$ power to detect a HR of 1.12 per s.D. change in TSH or FT4. For colorectal, breast and lung cancers, there was over $80 \%$ power to detect a HR of $1.32,1.33$ and 1.55 respectively per S.D. change in TSH or FT4.

There was an inverse relationship between TSH and prostate cancer risk in men (Table 3). Men with higher levels of TSH had a lower risk of prostate cancer with $P<0.05$ for TSH, log TSH and TSH quartiles after age and gender adjustment (model $\mathrm{A}$ ) and in the fully-adjusted model B. For each unit increase in TSH (in mIU/L) the adjusted risk of prostate cancer decreased by $30 \%$ (HR $=0.70,95 \%$ CI: $0.55-0.90, P=0.005$ ). Men in the highest quartile of TSH $(\geq 1.83 \mathrm{mIU} / \mathrm{L})$ had $56 \%$ lower risk $(\mathrm{HR}=0.44)$ of prostate cancer compared with men in the lowest quartile of TSH. Although men with TSH $<0.4 \mathrm{mIU} / \mathrm{L}$ had a higher risk of prostate cancer than men with TSH $0.4-4.0 \mathrm{mIU} / \mathrm{L}$, the number of men with low TSH was small, and the difference was not statistically significant (HR=1.87, 95\% CI: 0.63-4.60).

There was a positive relationship between FT4 and prostate cancer risk in men (Table 3). Men with higher levels of FT4 had higher risk of prostate cancer with $P<0.05$ for FT4, log FT4, and FT4 quartiles in the fullyadjusted model B. For each unit increase in FT4 (in $\mathrm{pmol} / \mathrm{L}$ ) the adjusted risk of prostate cancer increased by $11 \%$ (HR $=1.11,95 \%$ CI: $1.03-1.19, P=0.009)$. Men in the highest quartile of FT4 ( $\geq 17.45 \mathrm{pmol} / \mathrm{L}$ ) had $40 \%$ higher risk $(\mathrm{HR}=1.40)$ of prostate cancer compared with men in the lowest quartile of FT4 $(<14.50 \mathrm{pmol} / \mathrm{L})$.

In the fully-adjusted analysis, higher SPINA-GT was associated with an increased risk of prostate cancer $(\mathrm{HR}=1.93$, 95\% CI: 1.38-2.71) and higher TSHI was associated with a lower risk of prostate cancer $(\mathrm{HR}=0.39$, 95\% CI: 0.17-0.90) (Supplementary Table 1, see section on supplementary data given at the end of this article). Of the 1623 men included in the prostate cancer analysis, 1552 men also had measurements for SHBG and T. There was a positive correlation between TSH and SHBG $(r=0.06$, $P=0.013)$ and FT4 was not significantly correlated with SHBG, however there was a positive correlation between FT4 and T $(r=0.06, P=0.009)$ although the magnitude 
Table 1 Characteristics of the cohort and number of cancer outcomes overall and by gender. Data are shown as mean \pm s.D., percent or number (\%) of cancer outcomes.

\begin{tabular}{|c|c|c|c|}
\hline Characteristics & Men $(n=1623)$ & Women $(n=2026)$ & All $(n=3649)$ \\
\hline Age (years) & $51.3(14.9)$ & $51.5(15.5)$ & $51.4(15.2)$ \\
\hline \multicolumn{4}{|l|}{ Marital status } \\
\hline Married/living with partner & 83.7 & 74.8 & 78.8 \\
\hline Other & 16.3 & 25.2 & 21.2 \\
\hline \multicolumn{4}{|l|}{ Occupation } \\
\hline Managers/administrators & 24.6 & 9.5 & 16.2 \\
\hline Professionals & 13.9 & 13.2 & 13.5 \\
\hline Tradespersons & 13.0 & 1.7 & 6.7 \\
\hline Clerks/sales persons & 7.5 & 14.9 & 11.6 \\
\hline Plant operators/laborers & 11.0 & 28.6 & 20.8 \\
\hline Home duties & 0.0 & 11.7 & 6.5 \\
\hline Indept. means/pensioners & 25.0 & 14.0 & 18.9 \\
\hline Unknown & 5.0 & 6.4 & 5.8 \\
\hline \multicolumn{4}{|l|}{ Smoking status } \\
\hline Never & 41.6 & 60.8 & 52.3 \\
\hline Former & 42.9 & 28.7 & 35.0 \\
\hline Current & 15.5 & 10.5 & 12.7 \\
\hline \multicolumn{4}{|l|}{ Alcohol consumption } \\
\hline None & 3.5 & 8.3 & 6.2 \\
\hline Ex & 6.6 & 11.2 & 9.2 \\
\hline Light & 47.6 & 67.4 & 58.6 \\
\hline Moderate/heavy & 38.4 & 7.7 & 21.3 \\
\hline Unknown & 3.9 & 5.5 & 4.8 \\
\hline \multicolumn{4}{|l|}{ Menopausal status } \\
\hline Pre/OC use No & - & 36.4 & - \\
\hline Pre/OC use Yes & - & 11.5 & - \\
\hline Post/HRT use No & - & 35.7 & - \\
\hline Post/HRT use Yes & - & 16.4 & - \\
\hline \multicolumn{4}{|l|}{ Leisure time physical activity } \\
\hline$<150 \mathrm{~min} /$ week & 48.9 & 48.3 & 48.6 \\
\hline$\geq 150 \mathrm{~min} /$ week & 45.2 & 45.7 & 45.5 \\
\hline Ūnknown & 5.9 & 6.0 & 5.9 \\
\hline BMI $\left(k g / m^{2}\right)$ & $26.7(3.4)$ & $25.7(4.7)$ & $26.2(4.2)$ \\
\hline Diabetes & 5.7 & 5.6 & 5.6 \\
\hline TSH (mIU/L) & $1.41(0.91)$ & $1.54(1.11)$ & $1.48(1.03)$ \\
\hline logTSH & $0.18(0.57)$ & $0.25(0.61)$ & $0.22(0.59)$ \\
\hline \multicolumn{4}{|l|}{ TSH } \\
\hline Q1 & 25.4 & 24.7 & 25.0 \\
\hline Q2 & 28.0 & 22.5 & 24.9 \\
\hline Q3 & 23.9 & 26.4 & 25.3 \\
\hline Q4 & 22.7 & 26.5 & 24.8 \\
\hline \multicolumn{4}{|l|}{ TSH } \\
\hline$<0.4$ & 2.5 & 2.6 & 2.5 \\
\hline $0.4-4.0$ & 96.1 & 94.7 & 95.3 \\
\hline$>4.0$ & 1.4 & 2.7 & 2.1 \\
\hline FT4 (pmol/L) & $16.1(2.4)$ & $15.8(2.2)$ & $16.0(2.3)$ \\
\hline $\operatorname{logFT4}$ & $2.77(0.17)$ & $2.75(0.14)$ & $2.76(0.15)$ \\
\hline \multicolumn{4}{|l|}{ FT4 } \\
\hline Q1 & 23.4 & 26.6 & 25.1 \\
\hline Q2 & 23.3 & 25.5 & 24.5 \\
\hline Q3 & 25.7 & 26.1 & 25.9 \\
\hline Q4 & 27.7 & 21.9 & 24.4 \\
\hline TPOAb (kIU/mL) & $29.2(148.3)$ & $66.8(367.3)$ & $50.0(291.5)$ \\
\hline $\log T P O A b$ & $2.59(0.84)$ & $2.81(1.20)$ & $2.71(1.06)$ \\
\hline \multicolumn{4}{|l|}{ TPOAb } \\
\hline Q1 & 24.8 & 26.6 & 25.8 \\
\hline Q2 & 25.7 & 22.2 & 23.7 \\
\hline Q3 & 28.7 & 23.7 & 26.0 \\
\hline Q4 & 20.8 & 27.5 & 24.5 \\
\hline
\end{tabular}


Table 1 Continued

\begin{tabular}{l}
\hline Characteristics \\
\hline TPOAb \\
$<35.0$ \\
$\geq 35.0$ \\
SPINA-GT (pmol/s) \\
logSPINA-GT \\
TSHI \\
Cancer outcomes \\
Non-skin cancer \\
Prostate cancer \\
Breast cancer \\
Colorectal cancer \\
Lung cancer
\end{tabular}

\begin{tabular}{c}
\hline Men $(n=1623)$ \\
\hline 94.1 \\
5.9 \\
$4.61(3.06)$ \\
$1.41(0.45)$ \\
$1.25(0.22)$ \\
$299(18.4)$ \\
$126(7.8)$ \\
- \\
$52(3.2)$ \\
$20(1.2)$
\end{tabular}

\begin{tabular}{c}
\hline Women $(n=2026)$ \\
\hline 83.5 \\
16.5 \\
$4.40(2.75)$ \\
$1.36(0.47)$ \\
$1.27(0.24)$ \\
$301(14.9)$ \\
- \\
$100(4.9)$ \\
$51(2.5)$ \\
$21(1.0)$
\end{tabular}

\begin{tabular}{c}
\hline All $(n=3649)$ \\
\hline \\
88.2 \\
11.8 \\
$4.49(2.89)$ \\
$1.38(0.46)$ \\
$1.26(0.23)$ \\
$600(16.4)$ \\
- \\
- \\
$103(2.8)$ \\
$41(1.1)$
\end{tabular}

TSH quartiles (Q1: $<0.86$, Q2: 0.86 to $<1.25$, Q3: 1.25 to $<1.83$, Q4: $\geq 1.83$ mIU/L). FT4 quartiles (Q1: $<14.50$, Q2: 14.50 to $<16.00$, Q3: 16.00 to $<17.45$, Q4: $\geq 17.45 \mathrm{pmol} / \mathrm{L}$ ). To convert FT4 to $\mathrm{ng} / \mathrm{dL}$, multiply by 0.078 . TPOAb quartiles (Q1: $<5.01$, Q2: 5.01 to $<14.00, \mathrm{Q} 3: 14.00$ to $<21.10, \mathrm{Q} 4: \geq 21.10 \mathrm{kIU} / \mathrm{L}$ ). BMI, body mass index; FT4, free thyroxine T4; HRT, hormone replacement therapy; OC, oral contraceptives; SPINA-GT, measure of thyroid secretory capacity; TPOAb, anti-thyroid peroxidase antibodies; TSH, thyroid-stimulating hormone; TSHI, measure of pituitary thyrotroph function.

of these correlations were modest. Inclusion of both SHBG and $T$ in the fully-adjusted models did not change the relationship between TSH or FT4 with prostate cancer $(\mathrm{HR}=0.72,95 \% \mathrm{CI}: 0.56-0.93, P=0.011$ for $\mathrm{TSH}$ and $\mathrm{HR}=1.10,95 \% \mathrm{CI}: 1.02-1.19, P=0.014$ for FT4) (Supplementary Table 2).

Table 2 Adjusted hazard ratios for TSH, FT4 and TPOAb in relation to risk of all non-skin cancers in men and women ( $n=3649$ ).

\begin{tabular}{|c|c|c|c|c|c|}
\hline \multirow[b]{2}{*}{ Risk factor } & \multirow[b]{2}{*}{ Cancer cases } & \multicolumn{2}{|c|}{ Model A } & \multicolumn{2}{|c|}{ Model B } \\
\hline & & $\operatorname{HR}(95 \% \mathrm{Cl})$ & $P$-Value & $\mathrm{HR}(95 \% \mathrm{Cl})$ & $P$-Value \\
\hline TSH & 600 & $0.96(0.89,1.04)$ & 0.349 & $0.96(0.88,1.04)$ & 0.320 \\
\hline $\log T S H$ & 600 & $0.95(0.83,1.08)$ & 0.440 & $0.94(0.82,1.08)$ & 0.392 \\
\hline TSH & & & 0.576 & & 0.543 \\
\hline Q1 & 140 & 1.000 & & 1.000 & \\
\hline Q2 & 151 & $0.96(0.76,1.20)$ & & $0.95(0.75,1.19)$ & \\
\hline Q3 & 145 & $0.89(0.71,1.12)$ & & $0.87(0.69,1.10)$ & \\
\hline Q4 & 164 & $0.86(0.69,1.08)$ & & $0.86(0.68,1.09)$ & \\
\hline TSH & & & 0.243 & & 0.230 \\
\hline$<0.4$ & 9 & $0.60(0.31,1.16)$ & & $0.60(0.31,1.16)$ & \\
\hline $0.4-4.0$ & 578 & 1.000 & & 1.000 & \\
\hline$>4.0$ & 13 & $0.81(0.47,1.41)$ & & $0.80(0.46,1.38)$ & \\
\hline FT4 & 600 & $1.02(0.99,1.06)$ & 0.189 & $1.03(0.99,1.07)$ & 0.108 \\
\hline $\operatorname{logFT4}$ & 600 & $1.41(0.82,2.41)$ & 0.210 & $1.52(0.88,2.65)$ & 0.137 \\
\hline FT4 & & & 0.198 & & 0.083 \\
\hline Q1 & 165 & 1.000 & & 1.000 & \\
\hline Q2 & 132 & $0.88(0.70,1.11)$ & & $0.88(0.70,1.10)$ & \\
\hline Q3 & 150 & $0.98(0.79,1.23)$ & & $0.97(0.78,1.22)$ & \\
\hline Q4 & 153 & $1.14(0.91,1.42)$ & & $1.18(0.95,1.48)$ & \\
\hline $\log$ TPOAb & 600 & $1.01(0.93,1.09)$ & 0.877 & $1.00(0.92,1.08)$ & 0.919 \\
\hline TPOAb & & & 0.774 & & 0.901 \\
\hline Q1 & 132 & 1.000 & & 1.000 & \\
\hline Q2 & 140 & $0.97(0.76,1.23)$ & & $0.95(0.75,1.21)$ & \\
\hline Q3 & 168 & $1.09(0.86,1.37)$ & & $1.04(0.83,1.31)$ & \\
\hline Q4 & 160 & $1.04(0.82,1.31)$ & & $1.00(0.79,1.26)$ & \\
\hline TPOAb & & & 0.565 & & 0.469 \\
\hline$<35.0$ & 533 & 1.000 & & 1.000 & \\
\hline$\geq 35.0$ & 67 & $0.93(0.72,1.20)$ & & $0.91(0.70,1.18)$ & \\
\hline
\end{tabular}

HR: hazard ratio per unit change for continuous risk factor and relative to reference level for categorical risk factor. Model A includes TSH, FT4 or TPOAb adjusted for age and sex. Model B includes TSH, FT4 or TPOAb adjusted for age, sex, marital status, occupation, smoking, alcohol consumption, LTPA 150+ min/week, BMl, diabetes, menopausal status (women only), oral contraceptive use or hormone replacement therapy use (women only). TSH quartiles (Q1: $<0.86$, Q2: 0.86 to $<1.25, \mathrm{Q} 3: 1.25$ to $<1.83, \mathrm{Q} 4: \geq 1.83 \mathrm{mlU} / \mathrm{L}$ ). FT4 quartiles (Q1: $<14.50, \mathrm{Q} 2: 14.50$ to $<16.00, \mathrm{Q} 3: 16.00$ to $<17.45$, Q4: $\geq 17.45 \mathrm{pmol} / \mathrm{L}$ ). To convert FT4 to $\mathrm{ng} / \mathrm{dL}$, multiply by 0.078 . TPOAb quartiles (Q1: $<5.01$, Q2: 5.01 to $<14.00, \mathrm{Q} 3: 14.00$ to $<21.10, \mathrm{Q} 4: \geq 21.10 \mathrm{kIU} / \mathrm{L}$ ). 
Table 3 Adjusted hazard ratios for TSH, FT4 and TPOAb in relation to risk of prostate cancer in men $(n=1623)$.

\begin{tabular}{|c|c|c|c|c|c|}
\hline \multirow[b]{2}{*}{ Risk factor } & \multirow[b]{2}{*}{ Cancer cases } & \multicolumn{2}{|c|}{ Model A } & \multicolumn{2}{|c|}{ Model B } \\
\hline & & $\mathrm{HR}(95 \% \mathrm{Cl})$ & $P$-Value & $\operatorname{HR}(95 \% \mathrm{Cl})$ & $P$-Value \\
\hline TSH & 126 & $0.72(0.57,0.92)$ & 0.010 & $0.70(0.55,0.90)$ & 0.005 \\
\hline $\log T S H$ & 126 & $0.64(0.48,0.84)$ & 0.001 & $0.62(0.47,0.82)$ & 0.001 \\
\hline TSH & & & 0.020 & & 0.010 \\
\hline Q1 & 33 & 1.00 & & 1.00 & \\
\hline Q2 & 43 & $1.04(0.66,1.63)$ & & $1.00(0.63,1.57)$ & \\
\hline Q3 & 28 & $0.75(0.45,1.24)$ & & $0.72(0.43,1.20)$ & \\
\hline Q4 & 22 & $0.48(0.28,0.84)$ & & $0.44(0.25,0.76)$ & \\
\hline TSH & & & 0.547 & & 0.459 \\
\hline$<0.4$ & 4 & $1.70(0.63,4.60)$ & & $1.87(0.68,5.15)$ & \\
\hline $0.4-4.0$ & 120 & 1.00 & & 1.00 & \\
\hline$>4.0$ & 2 & $0.78(0.19,3.18)$ & & $0.81(0.20,3.32)$ & \\
\hline FT4 & 126 & $1.09(1.01,1.17)$ & 0.026 & $1.11(1.03,1.19)$ & 0.009 \\
\hline $\operatorname{logFT4}$ & 126 & $3.68(1.10,12.35)$ & 0.035 & $4.77(1.37,16.64)$ & 0.014 \\
\hline FT4 & & & 0.089 & & 0.046 \\
\hline Q1 & 34 & 1.00 & & 1.00 & \\
\hline Q2 & 20 & $0.63(0.36,1.09)$ & & $0.63(0.36,1.10)$ & \\
\hline Q3 & 34 & $1.03(0.64,1.65)$ & & $1.07(0.66,1.73)$ & \\
\hline Q4 & 38 & $1.27(0.80,2.03)$ & & $1.40(0.87,2.25)$ & \\
\hline $\log T P O A b$ & 126 & $0.87(0.69,1.10)$ & 0.239 & $0.89(0.69,1.13)$ & 0.327 \\
\hline TPOAb & & & 0.513 & & 0.719 \\
\hline Q1 & 26 & 1.00 & & 1.00 & \\
\hline Q2 & 39 & $1.19(0.73,1.97)$ & & $1.11(0.67,1.83)$ & \\
\hline Q3 & 37 & $1.01(0.61,1.66)$ & & $0.99(0.60,1.65)$ & \\
\hline Q4 & 24 & $0.81(0.46,1.41)$ & & $0.82(0.47,1.44)$ & \\
\hline TPOAb & & & 0.163 & & 0.211 \\
\hline$<35.0$ & 122 & 1.00 & & 1.00 & \\
\hline$\geq 35.0$ & 4 & $0.49(0.18,1.33)$ & & $0.53(0.19,1.44)$ & \\
\hline
\end{tabular}

HR: hazard ratio per unit change for continuous risk factor and relative to reference level for categorical risk factor. Model A includes TSH, FT4 or TPOAb adjusted for age. Model B includes TSH, FT4 or TPOAb adjusted for age, marital status, occupation, smoking, alcohol consumption, LTPA 150+ min/week, BMI, diabetes. TSH quartiles (Q1: $<0.86$, Q2; 0.86 to $<1.25$, Q3: 1.25 to $<1.83$, Q4: $\geq 1.83$ mIU/L). FT4 quartiles (Q1: $<14.50$, Q2: 14.50 to $<16.00$, Q3: 16.00 to $<17.45$, Q4: $\geq 17.45 \mathrm{pmol} / \mathrm{L}$ ). To convert FT4 to $\mathrm{ng} / \mathrm{dL}$, multiply by 0.078 . TPOAb quartiles (Q1: $<5.01, \mathrm{Q} 2: 5.01$ to $<14.00, \mathrm{Q} 3: 14.00$ to $<21.10$, Q4: $\geq 21.10 \mathrm{kIU} / \mathrm{L})$.

\section{Discussion}

In this population of community-dwelling men and women, thyroid hormones including TSH and FT 4 were not associated with incidence of all (non-skin) cancers: breast, lung or colorectal cancer. Lower TSH and higher FT4 were associated with an increased incidence of prostate cancer in men. These associations were independent of potential confounders, including sex hormone concentrations. There were no associations of TPOAb with the incidence of cancer in this cohort.

Few prospective studies have assessed the associations of thyroid function with cancer incidence, and these have shown conflicting results. With regard to all cancers combined, our results are similar to the Health In Men Study, in which no significant associations with TSH or FT4 were observed in 3836 men aged $\geq 70$ years whereby 863 men were diagnosed with cancer (median of 9 years follow-up) (25). By contrast, our results differ from the Rotterdam Study, which found an association of higher
FT4 with an increased risk of any solid cancer in 10318 men and women aged $\geq 45$ years followed for a median period of 10.4 years (23). While closer in age to our current cohort, the Rotterdam Study included a larger proportion of postmenopausal women ( $91.7 \%$ vs $52 \%$ ), and did not exclude participants with overt thyroid dysfunction (23). Of note, the Nord-Trøndelag Health Study which included 29691 men and women aged $\geq 20$ years reported an association of lower TSH $(<0.5 \mathrm{mIU} / \mathrm{L})$ with increased risk of all cancers, with stronger point estimates observed for those with overt compared to subclinical hyperthyroidism (24). Our study was adequately powered to detect modest associations of thyroid hormones with risk of all cancers. It is therefore possible that the associations observed in these cohorts were due to the inclusion of participants with more severe thyroid dysfunction. In our cohort, which excluded those with overt thyroid dysfunction and those who were on thyroid-related medications, no associations of TSH, FT4 or TPOAb were observed with the incidence of all (non-skin) cancers. 
Table 4 Adjusted hazard ratios for TSH, FT4 and TPOAb in relation to risk of breast cancer in women $(n=2026)$.

\begin{tabular}{|c|c|c|c|c|c|}
\hline \multirow[b]{2}{*}{ Risk factor } & \multirow[b]{2}{*}{ Cancer cases } & \multicolumn{2}{|c|}{ Model A } & \multicolumn{2}{|c|}{ Model B } \\
\hline & & $\mathrm{HR}(95 \% \mathrm{Cl})$ & $P$-Value & $\mathrm{HR}(95 \% \mathrm{Cl})$ & $P$-Value \\
\hline TSH & 100 & $0.89(0.72,1.10)$ & 0.286 & $0.89(0.72,1.11)$ & 0.298 \\
\hline $\log \mathrm{TSH}$ & 100 & $0.90(0.65,1.24)$ & 0.526 & $0.90(0.65,1.25)$ & 0.532 \\
\hline TSH & & & 0.619 & & 0.528 \\
\hline Q1 & 23 & 1.00 & & 1.00 & \\
\hline Q2 & 27 & $1.26(0.72,2.20)$ & & $1.30(0.74,2.27)$ & \\
\hline Q3 & 27 & $1.06(0.60,1.84)$ & & $1.00(0.57,1.75)$ & \\
\hline Q4 & 23 & $0.87(0.48,1.56)$ & & $0.85(0.47,1.54)$ & \\
\hline TSH & & & 0.338 & & 0.276 \\
\hline$<0.4$ & 1 & $0.37(0.05,2.62)$ & & $0.29(0.04,2.08)$ & \\
\hline $0.4-4.0$ & 98 & 1.00 & & 1.00 & \\
\hline$>4.0$ & 1 & $0.34(0.05,2.40)$ & & $0.35(0.05,2.53)$ & \\
\hline FT4 & 100 & $1.06(0.97,1.15)$ & 0.215 & $1.07(0.99,1.17)$ & 0.106 \\
\hline $\log \mathrm{FT} 4$ & 100 & $2.38(0.59,9.66)$ & 0.225 & $3.14(0.77,12.82)$ & 0.111 \\
\hline FT4 & & & 0.485 & & 0.322 \\
\hline Q1 & 26 & 1.00 & & 1.00 & \\
\hline Q2 & 21 & $0.85(0.48,1.51)$ & & $0.90(0.50,1.60)$ & \\
\hline Q3 & 26 & $1.04(0.61,1.80)$ & & $1.15(0.66,2.00)$ & \\
\hline Q4 & 27 & $1.32(0.77,2.26)$ & & $1.49(0.86,2.58)$ & \\
\hline $\log$ TPOAb & 100 & $1.02(0.87,1.20)$ & 0.770 & $0.99(0.84,1.16)$ & 0.865 \\
\hline TPOAb & & & 0.186 & & 0.324 \\
\hline Q1 & 27 & 1.00 & & 1.00 & \\
\hline Q2 & 14 & $0.60(0.31,1.15)$ & & $0.63(0.33,1.20)$ & \\
\hline Q3 & 30 & $1.22(0.72,2.05)$ & & $1.14(0.67,1.94)$ & \\
\hline Q4 & 29 & $1.01(0.59,1.71)$ & & $0.93(0.55,1.59)$ & \\
\hline TPOAb & & & 0.929 & & 0.706 \\
\hline$<35.0$ & 83 & 1.00 & & 1.00 & \\
\hline$\geq 35.0$ & 17 & $1.02(0.61,1.73)$ & & $0.90(0.53,1.53)$ & \\
\hline
\end{tabular}

HR: hazard ratio per unit change for continuous risk factor and relative to reference level for categorical risk factor. Model A includes TSH, FT4 or TPOAb adjusted for age. Model B includes TSH, FT4 or TPOAb adjusted for age, marital status, occupation, smoking, alcohol consumption, LTPA 150+ min/week, $\mathrm{BMI}$, diabetes, menopausal status, oral contraceptive use or hormone replacement therapy use. TSH quartiles (Q1: $<0.86$, Q2: 0.86 to $<1.25$, Q3: 1.25 to $<1.83$, Q4: $\geq 1.83 \mathrm{mIU} / \mathrm{L}$ ). FT4 quartiles (Q1: $<14.50, \mathrm{Q} 2: 14.50$ to $<16.00, \mathrm{Q3}: 16.00$ to $<17.45$, Q4: $\geq 17.45$ pmol/L). To convert FT4 to ng/dL, multiply by 0.078. TPOAb quartiles (Q1: $<5.01$, Q2: 5.01 to $<14.00, \mathrm{Q} 3: 14.00$ to $<21.10, \mathrm{Q} 4: 21.10 \mathrm{kIU} / \mathrm{L}$ ).

Our results showed an association of lower TSH and higher FT4 as well as increased thyroid secretory capacity and decreased thyrotroph sensitivity with prostate cancer risk in men aged 25-84 years. This association was independent of $\mathrm{T}$ and SHBG concentrations. Our results are similar to the Nord-Trøndelag Health Study which included men of a similar age span to our cohort ( $\geq 20$ years) (24). In that study, TSH $<0.5 \mathrm{mIU} / \mathrm{L}$ was associated with an increased risk of prostate cancer in men, however that study did not assess associations with FT4 and did not adjust for SHBG and T concentrations (24). A prospective case-control study involving 401 cases and 800 controls in a population of middle-aged male smokers found an association of hypothyroidism with decreased prostate cancer risk, but no association of hyperthyroidism and prostate cancer based on nine cases of prostate cancer in the hyperthyroid group. In that study, higher TSH was also inversely associated with prostate cancer, however no associations of FT4 or total thyroxine with prostate cancer were observed (20).
The Rotterdam Study that included middle-aged and older men (aged $\geq 45$ years) found an association of FT4 but not TSH with the risk of prostate cancer after adjusting for confounders (23), whereas in the Health In Men Study (in which participants were older) no associations of TSH or FT4 with prostate cancer (340 cases) were observed (25). Data linkage to the cancer registry was utilized for outcome measure ascertainment in all cohorts and is therefore unlikely to account for inconsistencies in the observed results. Moreover, the Health In Men Study was also based in Western Australia and used the same data linkage system as our current study. Our study demonstrates an association of increased thyroid hormone exposure with higher risk of prostate cancer. Thyroid gland disorders have been associated with changes in sex steroid metabolism and SHBG concentrations (38). Furthermore, downregulation of aromatase activity in immature rat Sertoli cells by $\mathrm{T} 3$ have been demonstrated $(39,40)$, and T3 has also been shown to induce secretion of sex hormones in the testes through 
Table 5 Adjusted hazard ratios for TSH, FT4 and TPOAb in relation to risk of colorectal cancer in men and women ( $n=3649$ ).

\begin{tabular}{|c|c|c|c|c|c|}
\hline \multirow[b]{2}{*}{ Risk factor } & \multirow[b]{2}{*}{ Cancer cases } & \multicolumn{2}{|c|}{ Model A } & \multicolumn{2}{|c|}{ Model B } \\
\hline & & HR $(95 \% \mathrm{Cl})$ & $P$-Value & $\mathrm{HR}(95 \% \mathrm{Cl})$ & $P$-Value \\
\hline TSH & 103 & $0.96(0.79,1.17)$ & 0.702 & $0.96(0.79,1.18)$ & 0.712 \\
\hline $\log \mathrm{TSH}$ & 103 & $0.91(0.66,1.25)$ & 0.546 & $0.91(0.66,1.25)$ & 0.544 \\
\hline TSH & & & 0.335 & & 0.291 \\
\hline Q1 & 29 & 1.00 & & 1.00 & \\
\hline Q2 & 24 & $0.73(0.42,1.25)$ & & $0.70(0.41,1.21)$ & \\
\hline Q3 & 20 & $0.59(0.34,1.05)$ & & $0.58(0.33,1.03)$ & \\
\hline Q4 & 30 & $0.75(0.45,1.27)$ & & $0.74(0.44,1.24)$ & \\
\hline TSH & & & 0.631 & & 0.601 \\
\hline$<0.4$ & 1 & $0.39(0.05,2.79)$ & & $0.38(0.05,2.72)$ & \\
\hline $0.4-4.0$ & 99 & 1.00 & & 1.00 & \\
\hline$>4.0$ & 3 & $1.11(0.35,3.51)$ & & $1.17(0.37,3.72)$ & \\
\hline FT4 & 103 & $1.01(0.93,1.10)$ & 0.826 & $1.01(0.93,1.10)$ & 0.829 \\
\hline logFT4 & 103 & $1.15(0.32,4.13)$ & 0.825 & $1.17(0.33,4.18)$ & 0.815 \\
\hline FT4 & & & 0.552 & & 0.529 \\
\hline Q1 & 23 & 1.00 & & 1.00 & \\
\hline Q2 & 27 & $1.36(0.78,2.37)$ & & $1.37(0.78,2.40)$ & \\
\hline Q3 & 26 & $1.24(0.71,2.18)$ & & $1.23(0.70,2.16)$ & \\
\hline Q4 & 27 & $1.49(0.85,2.60)$ & & $1.50(0.85,2.64)$ & \\
\hline $\operatorname{logTPOAb}$ & 103 & $1.17(0.99,1.38)$ & 0.063 & $1.16(0.99,1.37)$ & 0.074 \\
\hline TPOAb & & & 0.122 & & 0.131 \\
\hline Q1 & 21 & 1.00 & & 1.00 & \\
\hline Q2 & 17 & $0.74(0.39,1.40)$ & & $0.72(0.38,1.37)$ & \\
\hline Q3 & 29 & $1.17(0.67,2.05)$ & & $1.15(0.65,2.03)$ & \\
\hline Q4 & 36 & $1.46(0.85,2.51)$ & & $1.43(0.83,2.46)$ & \\
\hline TPOAb & & & 0.067 & & 0.065 \\
\hline$<35.0$ & 85 & 1.00 & & 1.00 & \\
\hline$\geq 35.0$ & 18 & $1.63(0.97,2.74)$ & & $1.64(0.97,2.78)$ & \\
\hline
\end{tabular}

HR: hazard ratio per unit change for continuous risk factor and relative to reference level for categorical risk factor. Model A includes TSH, FT4 or TPOAb adjusted for age and sex. Model B includes TSH, FT4 or TPOAb adjusted for age, sex, marital status, occupation, smoking, alcohol consumption, LTPA 150+ min/week, BMI, diabetes, menopausal status (women only), oral contraceptive use or hormone replacement therapy use (women only) TSH quartiles (Q1: $<0.86$, Q2: 0.86 to $<1.25$, Q3: 1.25 to $<1.83$, Q4: $\geq 1.83$ mIU/L). FT4 quartiles (Q1: $<14.50, \mathrm{Q} 2: 14.50$ to $<16.00, \mathrm{Q} 3: 16.00$ to $<17.45$, Q4: $\geq 17.45 \mathrm{pmol} / \mathrm{L}$ ). To convert FT4 to $\mathrm{ng} / \mathrm{dL}$, multiply by 0.078 . TPOAb quartiles (Q1: $<5.01, \mathrm{Q} 2: 5.01$ to $<14.00, \mathrm{Q} 3: 14.00$ to $<21.10, \mathrm{Q} 4: \geq 21.10 \mathrm{kIU} / \mathrm{L}$ ).

direct and indirect pathways (38). The relationship of TSH and FT4 with prostate cancer was not explained by potential effects of thyroid hormones on the gonadal axis in our study, however we were not able to measure local production or metabolism of sex hormones. In vitro studies have shown that thyroid hormone receptor is expressed in human prostatic epithelium cell lines, and proliferative effects of T3 have been demonstrated on the LNCaP prostate cancer cell line $(41,42)$. This is mediated through downregulation of the B-cell translocation gene 2 (BTG2), a gene involved in cell-cycle regulation (42). It is therefore possible that prostate cancer growth may be modulated by thyroid hormone levels, however these associations may differ according to the age characteristics of the cohort studied.

Conflicting results for the association of thyroid hormones and thyroid antibodies with breast cancer risk have been reported in the literature. The Rotterdam Study, which consisted of predominantly post-menopausal women, found an association of higher FT4 with a higher incidence of breast cancer (23). Of the 5698 women in that cohort, 227 women were diagnosed with breast cancer. When women taking thyroid or anti-thyroid medications were excluded in the Rotterdam Study, the associations of higher FT4 and breast cancer risk were no longer significant, possibly due to loss of power (214 vs 227 events) (23). Another prospective case-control study of predominantly post-menopausal women involving 676 cases and 680 controls also found a positive association of FT4 and breast cancer risk (22). Conversely, a study of postmenopausal women found that breast cancer was related to an earlier diagnosis of hypothyroidism, use of thyroid medications and lower FT4 levels (21). No association of TSH and the incidence of breast cancer was observed in the Nord-Trøndelag Health Study, which included a broader age range of women with 370 breast cancer events (24). Higher TPOAb concentrations were associated with a lower incidence of breast cancer in one prospective case-control study (676 cases and 680 controls) (22), but no associations were observed in 
Table 6 Adjusted hazard ratios for TSH, FT4 and TPOAb in relation to risk of lung cancer in men and women ( $n=3649)$.

\begin{tabular}{|c|c|c|c|c|c|}
\hline \multirow[b]{2}{*}{ Risk factor } & \multirow[b]{2}{*}{ Cancer cases } & \multicolumn{2}{|c|}{ Model A } & \multicolumn{2}{|c|}{ Model B } \\
\hline & & $\mathrm{HR}(95 \% \mathrm{Cl})$ & $P$-Value & $\mathrm{HR}(95 \% \mathrm{Cl})$ & $P$-Value \\
\hline TSH & 41 & $0.92(0.67,1.27)$ & 0.613 & $0.95(0.69,1.31)$ & 0.744 \\
\hline logTSH & 41 & $0.97(0.59,1.60)$ & 0.898 & $1.03(0.62,1.72)$ & 0.914 \\
\hline TSH & & & 0.643 & & 0.705 \\
\hline Q1 & 6 & 1.00 & & 1.00 & \\
\hline Q2 & 12 & $1.71(0.64,4.57)$ & & $1.69(0.63,4.57)$ & \\
\hline Q3 & 12 & $1.63(0.61,4.35)$ & & $1.71(0.63,4.62)$ & \\
\hline Q4 & 11 & $1.21(0.44,3.29)$ & & $1.39(0.50,3.88)$ & \\
\hline TSH & & & 0.999 & & 0.989 \\
\hline$<0.4$ & 1 & $0.95(0.13,6.94)$ & & $0.86(0.12,6.39)$ & \\
\hline $0.4-4.0$ & 40 & 1.00 & & 1.00 & \\
\hline$>4.0$ & 0 & - & & - & \\
\hline FT4 & 41 & $1.06(0.93,1.21)$ & 0.383 & $1.05(0.92,1.20)$ & 0.479 \\
\hline $\operatorname{logFT4}$ & 41 & $2.55(0.31,20.70)$ & 0.382 & $2.19(0.26,18.79)$ & 0.475 \\
\hline FT4 & & & 0.300 & & 0.262 \\
\hline Q1 & 11 & 1.00 & & 1.00 & \\
\hline Q2 & 11 & $1.18(0.51,2.73)$ & & $1.13(0.48,2.65)$ & \\
\hline Q3 & 6 & $0.62(0.23,1.66)$ & & $0.58(0.21,1.58)$ & \\
\hline Q4 & 13 & $1.54(0.69,3.45)$ & & $1.53(0.67,3.48)$ & \\
\hline $\operatorname{logTPOAb}$ & 41 & $0.98(0.72,1.33)$ & 0.893 & $0.98(0.72,1.33)$ & 0.879 \\
\hline TPOAb & & & 0.577 & & 0.514 \\
\hline Q1 & 6 & 1.00 & & 1.00 & \\
\hline Q2 & 10 & $1.45(0.52,3.99)$ & & $1.78(0.63,5.01)$ & \\
\hline Q3 & 10 & $1.35(0.49,3.72)$ & & $1.47(0.52,4.12)$ & \\
\hline Q4 & 15 & $1.92(0.74,4.98)$ & & $2.05(0.78,5.44)$ & \\
\hline TPOAb & & & 0.088 & & 0.090 \\
\hline$<35.0$ & 40 & 1.00 & & 1.00 & \\
\hline$\geq 35.0$ & 1 & $0.18(0.02,1.29)$ & & $0.18(0.02,1.31)$ & \\
\hline
\end{tabular}

HR: hazard ratio per unit change for continuous risk factor and relative to reference level for categorical risk factor. Model A includes TSH, FT4 or TPOAb adjusted for age and sex. Model B includes TSH, FT4 or TPOAb adjusted for age, sex, marital status, occupation, smoking, alcohol consumption, LTPA 150+ min/week, BMI, diabetes, menopausal status (women only), oral contraceptive use or hormone replacement therapy use (women only). TSH quartiles (Q1: $<0.86, \mathrm{Q} 2: 0.86$ to $<1.25, \mathrm{Q} 3: 1.25$ to $<1.83, \mathrm{Q} 4: \geq 1.83 \mathrm{mIU} / \mathrm{L})$. FT4 quartiles (Q1: $<14.50, \mathrm{Q} 2: 14.50$ to $<16.00, \mathrm{Q} 3: 16.00$ to $<17.45$, Q4: $\geq 17.45 \mathrm{pmol} / \mathrm{L})$. To convert FT4 to $\mathrm{ng} / \mathrm{dL}$, multiply by 0.078 . TPOAb quartiles (Q1: $<5.01, \mathrm{Q} 2: 5.01$ to $<14.00, \mathrm{Q} 3: 14.00$ to $<21.10, \mathrm{Q} 4: \geq 21.10 \mathrm{kIU} / \mathrm{L}$ ).

another prospective study whereby 56 breast cancer events occurred (21). Results from our study, which consisted of approximately equal proportions of pre- and postmenopausal women, do not support an association of thyroid hormones or TPOAb with breast cancer, however weak to modest associations of thyroid hormones and breast cancer risk may have been missed due to a smaller number of breast cancer cases in our study.

In older men, higher TSH has been associated with an increased incidence of colorectal cancer (25). This is in contrast to neutral associations of thyroid hormones and colorectal cancer observed in the current cohort. Whilst we had moderate power to detect an association of thyroid hormones with colorectal cancer, our results are in keeping with other cohorts, which have included both men and women spanning over a wider age range. These studies have reported no associations of thyroid hormones with colorectal cancer (857 events) (24), or a broader range of gastrointestinal cancers (353 events) (23). Overall, these results do not suggest a role for thyroid hormones in modulating colorectal cancer growth, however further studies are warranted to assess if associations differ according to the age and sex of the cohort studied. An association of lower TSH or higher FT4 with lung cancer has previously been found $(23,24)$. This was not observed in the current study, however there was limited power to observe significant associations with lung cancer in this study.

We acknowledge several limitations associated with this study. This is an observational study and therefore causality cannot be inferred. The study population consisted predominantly of men and women of AngloCeltic background, therefore results cannot be extended to other ethnicities. Single measures of thyroid hormones were available, however serial measurements were not collected, and results for T3 were not available. Thyroid hormone measurements from 2007 had to be re-calibrated to match the 2011/2013 methods. Strengths of our study include a large population-based cohort spanning a wide range of ages with a long period of follow-up. Detailed 
clinical and biochemical assessment at baseline allowed for systematic adjustment of potential confounders. Cancer diagnoses were based on data linkage to the cancer registry, allowing for near-complete capture of all clinically relevant cancers.

In conclusion, in a population of communitydwelling men and women spanning a wide range of ages who did not have overt thyroid dysfunction and were not on thyroid-related medications, serum TSH, FT4 and TPOAb were not associated with the incidence of all (nonskin) cancers: breast, colorectal or lung cancer. In men, lower TSH and higher FT4, overall signifying an increased exposure to thyroid hormones, were associated with an increased incidence of prostate cancer. Further studies are warranted to clarify whether greater exposure to thyroid hormone is a biomarker or a contributory factor to prostate cancer in men.

\section{Supplementary data}

This is linked to the online version of the paper at http://dx.doi.org/10.1530/ EJE-17-0197.

\section{Declaration of interest}

The authors declare that there is no conflict of interest that could be perceived as prejudicing the impartiality of the research reported.

\section{Funding}

The 1994/1995 Busselton Health Survey was supported and funded by the Health Promotion Foundation of Western Australia. The funding sources had no involvement in the planning, analysis and writing of the manuscript.

\section{Acknowledgements}

The authors thank the staff of the Western Australian Data Linkage Branch, the Cancer Registry and Registrar General's Office for their assistance in providing linked data. The authors especially thank the Busselton men and women who took part in the survey and the Busselton Population Medical Research Institute for access to the survey data and specimens.

\section{References}

1 Pinto M, Soares P \& Ribatti D. Thyroid hormone as a regulator of tumor induced angiogenesis. Cancer Letters 2011301 119-126. (doi:10.1016/j.canlet.2010.11.011)

2 Cao X, Kambe F, Moeller LC, Refetoff S \& Seo H. Thyroid hormone induces rapid activation of Akt/protein kinase B-mammalian target of rapamycin-p70S6K cascade through phosphatidylinositol 3-kinase in human fibroblasts. Molecular Endocrinology 200519 102-112. (doi:10.1210/me.2004-0093)

3 Cao X, Kambe F, Yamauchi M \& Seo H. Thyroid-hormone-dependent activation of the phosphoinositide 3-kinase/Akt cascade requires Src and enhances neuronal survival. Biochemical Journal 2009424 201-209. (doi:10.1042/BJ20090643)
4 Chalhoub N \& Baker SJ. PTEN and the PI3-kinase pathway in cancer Annual Review of Pathology 20094 127-150. (doi:10.1146/annurev. pathol.4.110807.092311)

5 Moeller LC, Dumitrescu AM \& Refetoff S. Cytosolic action of thyroid hormone leads to induction of hypoxia-inducible factor-1alpha and glycolytic genes. Molecular Endocrinology 200519 2955-2963. (doi:10.1210/me.2004-0542)

6 Davis PJ, Davis FB, Mousa SA, Luidens MK \& Lin HY. Membrane receptor for thyroid hormone: physiologic and pharmacologic implications. Annual Review of Pharmacology Toxicology 201151 99-115. (doi:10.1146/annurev-pharmtox-010510-100512)

7 Davis FB, Mousa SA, O'Connor L, Mohamed S, Lin HY, Cao HJ \& Davis PJ. Proangiogenic action of thyroid hormone is fibroblast growth factor-dependent and is initiated at the cell surface. Circulation Research 200494 1500-1506. (doi:10.1161/ 01.RES.0000130784.90237.4a)

8 Ciavardelli D, Bellomo M, Crescimanno C \& Vella V. Type 3 deiodinase: role in cancer growth, stemness, and metabolism. Frontiers in Endocrinology 20145 215. (doi:10.3389/fendo.2014.00215)

9 Selva DM \& Hammond GL. Thyroid hormones act indirectly to increase sex hormone-binding globulin production by liver via hepatocyte nuclear factor-4alpha. Journal of Molecular Endocrinology 200943 19-27. (doi:10.1677/JME-09-0025)

10 Brenta G, Schnitman M, Gurfinkiel M, Damilano S, Pierini A, Sinay I \& Pisarev MA. Variations of sex hormone-binding globulin in thyroid dysfunction. Thyroid 19999 273-277. (doi:10.1089/thy.1999.9.273)

11 Theodossiou C \& Schwarzenberger P. Propylthiouracil reduces xenograft tumor growth in an athymic nude mouse prostate cancer model. American Journal of Medical Sciences 2000319 96-99. (doi:10.1016/S0002-9629(15)40695-0)

12 Theodossiou C, Skrepnik N, Robert EG, Prasad C, Axelrad TW, Schapira DV \& Hunt JD. Propylthiouracil-induced hypothyroidism reduces xenograft tumor growth in athymic nude mice. Cancer 199986 1596-1601. (doi:10.1002/(SICI)10970142(19991015)86:8<1596::AID-CNCR30>3.0.CO;2-C)

13 Catalano V, Dentice M, Ambrosio R, Luongo C, Carollo R, Benfante A, Todaro M, Stassi G \& Salvatore D. Activated thyroid hormone promotes differentiation and chemotherapeutic sensitization of colorectal cancer stem cells by regulating Wnt and BMP4 signaling. Cancer Research 201676 1237-1244. (doi:10.1158/0008-5472. CAN-15-1542)

14 Disel U, Besen A, Karadeniz C, Mertsoylu H, Sezer A, Kose F, TanerSumbul A, Gurkut O, Muallaoglu S, Abali H et al. Prevalence of thyroid dysfunction in untreated cancer patients: a cross-sectional study. Medical Oncology 201229 3608-3613. (doi:10.1007/s12032012-0254-4)

15 Reddy A, Dash C, Leerapun A, Mettler TA, Stadheim LM, Lazaridis $\mathrm{KN}$, Roberts RO \& Roberts LR. Hypothyroidism: a possible risk factor for liver cancer in patients with no known underlying cause of liver disease. Clinical Gastroenterology and Hepatology 20075 118-123. (doi:10.1016/j.cgh.2006.07.011)

16 Simon MS, Tang MT, Bernstein L, Norman SA, Weiss L, Burkman RT, Daling JR, Deapen D, Folger SG, Malone K et al. Do thyroid disorders increase the risk of breast cancer? Cancer Epidemiology Biomarkers and Prevention 200211 1574-1578.

17 Cristofanilli M, Yamamura Y, Kau SW, Bevers T, Strom S, Patangan M, Hsu L, Krishnamurthy S, Theriault RL \& Hortobagyi GN. Thyroid hormone and breast carcinoma. Primary hypothyroidism is associated with a reduced incidence of primary breast carcinoma. Cancer 2005 103 1122-1128. (doi:10.1002/cncr.20881)

18 Ness RB, Grisso JA, Cottreau C, Klapper J, Vergona R, Wheeler JE, Morgan M \& Schlesselman JJ. Factors related to inflammation of the ovarian epithelium and risk of ovarian cancer. Epidemiology $2000 \mathbf{1 1}$ 111-117. (doi:10.1097/00001648-200003000-00006)

19 Ko AH, Wang F \& Holly EA. Pancreatic cancer and medical history in a population-based case-control study in the San Francisco Bay Area, 
California. Cancer Causes and Control 200718 809-819. (doi:10.1007/ s10552-007-9024-6)

20 Mondul AM, Weinstein SJ, Bosworth T, Remaley AT, Virtamo J \& Albanes D. Circulating thyroxine, thyroid-stimulating hormone, and hypothyroid status and the risk of prostate cancer. PLOS ONE 20127 e47730. (doi:10.1371/journal.pone.0047730)

21 Kuijpens JL, Nyklictek I, Louwman MW, Weetman TA, Pop VJ \& Coebergh JW. Hypothyroidism might be related to breast cancer in post-menopausal women. Thyroid 200515 1253-1259. (doi:10.1089/ thy.2005.15.1253)

22 Tosovic A, Becker C, Bondeson AG, Bondeson L, Ericsson UB, Malm J \& Manjer J. Prospectively measured thyroid hormones and thyroid peroxidase antibodies in relation to breast cancer risk. International Journal of Cancer 2012131 2126-2133. (doi:10.1002/ijc.27470)

23 Khan SR, Chaker L, Ruiter R, Aerts JG, Hofman A, Dehghan A, Franco $\mathrm{OH}$, Stricker BH \& Peeters RP. Thyroid function and cancer risk: the Rotterdam Study. Journal of Clinical Endocrinology and Metabolism 2016 101 5030-5036. (doi:10.1210/jc.2016-2104)

24 Hellevik AI, Asvold BO, Bjoro T, Romundstad PR, Nilsen TI \& Vatten LJ. Thyroid function and cancer risk: a prospective population study. Cancer Epidemiology Biomarkers and Prevention 200918 570-574. (doi:10.1158/1055-9965.EPI-08-0911)

25 Chan YX, Alfonso H, Chubb SA, Fegan PG, Hankey GJ, Golledge J, Flicker L \& Yeap BB. Higher thyrotropin concentration is associated with increased incidence of colorectal cancer in older men. Clinical Endocrinology 201686 278-285. (doi:10.1111/cen.13271)

26 Giani C, Fierabracci P, Bonacci R, Gigliotti A, Campani D, De Negri F, Cecchetti D, Martino E \& Pinchera A. Relationship between breast cancer and thyroid disease: relevance of autoimmune thyroid disorders in breast malignancy. Journal of Clinical Endocrinology and Metabolism 199681 990-994. (doi.10.1210/ jc.81.3.990)

27 Taylor PN, Razvi S, Pearce SH \& Dayan CM. Clinical review: a review of the clinical consequences of variation in thyroid function within the reference range. Journal of Clinical Endocrinology and Metabolism 201398 3562-3571. (doi:10.1210/jc.2013-1315)

28 Knuiman MW, Jamrozik K, Welborn TA, Bulsara MK, Divitini ML \& Whittall DE. Age and secular trends in risk factors for cardiovascular disease in Busselton. Australian Journal of Public Health 199519 375-382. (doi:10.1111/j.1753-6405.1995.tb00389.x)

29 Knuiman MW, Hung J, Divitini ML, Davis TM \& Beilby JP. Utility of the metabolic syndrome and its components in the prediction of incident cardiovascular disease: a prospective cohort study. European Journal of Cardiovascular Prevention and Rehabilitation 200916 235-241. (doi:10.1097/HJR.0b013e32832955fc)

30 Li M, Eastman CJ, Waite KV, Ma G, Zacharin MR, Topliss DJ, Harding PE, Walsh JP, Ward LC, Mortimer RH et al. Are Australian children iodine deficient? Results of the Australian National Iodine Nutrition Study. Medical Journal of Australia 2006184 165-169.

31 Australian Institute of Health and Welfare. The Active Australia Survey: a guide and manual for implementing analysis and reporting. Australian Institute of Health and Welfare Cat. No. CVD 22, 2003.
32 Walsh JP, Bremner AP, Feddema P, Leedman PJ, Brown SJ \& $\mathrm{O}^{\prime}$ Leary P. Thyrotropin and thyroid antibodies as predictors of hypothyroidism: a 13-year, longitudinal study of a community-based cohort using current immunoassay techniques. Journal of Clinical Endocrinology and Metabolism 201095 1095-1104. (doi.10.1210/ jc.2009-1977)

33 Brown SJ, Bremner AP, Hadlow NC, Feddema P, Leedman PJ, O'Leary PC \& Walsh JP. The log TSH-free T4 relationship in a communitybased cohort is nonlinear and is influenced by age, smoking and thyroid peroxidase antibody status. Clinical Endocrinology 201685 789-796. (doi:10.1111/cen.13107)

34 Yeap BB, Knuiman MW, Divitini ML, Handelsman DJ, Beilby JP, Beilin J, McQuillan B \& Hung J. Differential associations of testosterone, dihydrotestosterone and oestradiol with physical, metabolic and health-related factors in community-dwelling men aged 17-97 years from the Busselton Health Survey. Clinical Endocrinology 201481 100-108. (doi:10.1111/cen.12407)

35 Holman CD, Bass AJ, Rouse IL \& Hobbs MS. Population-based linkage of health records in Western Australia: development of a health services research linked database. Australia and New Zealand Journal of Public Health 199923 453-459. (doi:10.1111/j.1467-842X.1999. tb01297.x)

36 Dietrich JW, Landgrafe-Mende G, Wiora E, Chatzitomaris A, Klein HH, Midgley JE \& Hoermann R. Calculated parameters of thyroid homeostasis: emerging tools for differential diagnosis and clinical research. Frontiers in Endocrinology 20167 57. (doi:10.3389/ fendo.2016.00057)

37 Jostel A, Ryder WDJ \& Shalet SM. The use of thyroid function tests in the diagnosis of hypopituitarism: definition and evaluation of the TSH Index. Clinical Endocrinology 200971 529-534. (doi:10.1111/ j.1365-2265.2009.03534.x)

38 Maran RRM. Thyroid hormones: their role in testicular steroidogenesis. Archives of Andrology 200349 375-388. (doi:10.1080/01485010390204968)

39 Catalano S, Pezzi V, Chimento A, Giordano C, Carpino A, Young M, McPhaul MJ \& Ando S. Triiodothyronine decreases the activity of the proximal promoter (PII) of the aromatase gene in the mouse sertoli cell line, TM4. Molecular Endocrinology 200317 923-934. (doi:10.1210/me.2002-0102)

40 Ando S, Sirianni R, Forasteri P, Casaburi I, Lanzino M, Rago V, Giordano F, Giordano C, Carpino A \& Pezzi V. Aromatase expression in prepuberal Sertoli cells: effect of thyroid hormone. Molecular and Cellular Endocrinology 2001178 11-21. (doi:10.1016/S03037207(01)00443-9)

41 Hsieh ML \& Juang HH. Cell growth effects of triiodothyronine and expression of thyroid hormone receptor in prostate carcinoma cells. Journal of Andrology 200526 422-428. (doi:10.2164/ jandrol.04162)

42 Tsui KH, Hsieh WC, Lin MH, Chang PL \& Juang HH. Triiodothyronine modulates cell proliferation of human prostatic carcinoma cells by downregulation of the B-cell translocation gene 2. Prostate 200868 610-619. (doi:10.1002/pros.20725)
Received 9 March 2017

Revised version received 9 June 2017

Accepted 6 July 2017 